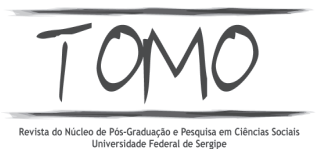

\author{
AS ELITES PARANAENSES \\ E A DEMOCRACIA: \\ explorando a estruturara dimensional e \\ os determinantes dos seus valores e \\ atitudes politicas
}

\author{
Ednaldo Aparecido Ribeiro* \\ Bruno Bolognesi**
}

\title{
Apresentação
}

Apesar da questão da importância ou não de fatores culturais nos fenômenos políticos ainda continuar alimentando polêmicas consideráveis no interior da ciência política praticada nos dias de hoje, dificilmente podemos encontrar investigadores que ostensivamente afirmem a total irrelevância dessa dimensão subjetiva. Ainda que o tema da causalidade e da capacidade explicativa de variáveis relacionadas à cultura política seja controverso (MULLER \& SELIGSON, 1994), a tese de que tais fatores importam tem cada vez mais ganhado força (PUTNAM, 1997; DALTON, 2000; NORRIS, 2002; INGLEHART \& WELZEL, 2005). Mesmo entre pesquisadores não vinculados ao que podemos chamar de abordagem culturalista têm se difundido a tese de que o conjunto de variáveis relacionadas a essa dimensão subjetiva deve ser considerado, ainda

Professor de Ciências Sociais da Universidade Estadual de Maringá.

** Mestrando do Programa de Pós-graduação em Sociologia da Universidade Federal do Paranáe pesquisador do Núcleo de Pesquisa em Sociologia Política Brasileira (NUSP/UFPR). É bolsista CAPES.

\begin{tabular}{l|ll|l|l|}
\hline TOMO & São & Cristóvão-SE & NN$^{0} 12$ & jan./jun. 2008 \\
\hline
\end{tabular}


que na posição de variável interveniente, em qualquer análise multicausal dos problemas contemporâneos, sobretudo aqueles relacionados ao tema da democracia (DAHL, 1997).

O presente artigo se estrutura sobre essa hipótese fundamental e também sobre algumas questões interessantes que dela derivam: se os sistemas de crenças, valores e atitudes políticas são importantes dimensões dos fenômenos contemporâneos, a cultura de quem importa? As orientações políticas das elites políticas, diretamente envolvidas na vida pública de uma sociedade específica, teriam maior relevância do que aquelas compartilhadas pelos cidadãos médios? Seria a cultura política dessa elite mais sofisticada e dotada de maior consistência interna? Tais perguntas fazem ainda mais sentido quando partimos do pressuposto que elites sempre existiram historicamente (MOSCA 1992; MICHELS, 2001) e que estas elites estão no controle do processo decisório não somente neste recorte específico, mas em todos os estudos sobre democracias modernas.

Sobre as primeiras interrogações a literatura especializada, que discutiremos brevemente nesse trabalho, tem afirmado que o impacto dos valores partilhados pela elite é maior em termos relativos, sendo fundamentais na configuração de situações políticas específicas. A última questão, todavia, tem se mantido circunscrita ao campo dos pressupostos teóricos não testados, sobretudo devido às dificuldades metodológicas envolvidas na operacionalização das análises que poderiam conduzir a respostas satisfatórias. A comparação entre elites e não-elites em uma mesma sociedade envolveria a realização de surveys representativos para essas duas populações, o que torna a tarefa realmente complexa.

Não pretendemos com esse trabalho levar a cabo tal tarefa, mas acreditamos que apesar de não possuirmos recursos para realizar o procedimento comparativo, possamos contribuir de maneira modesta para a discussão desse ponto. Utilizando informações sobre um conjunto de valores e atitudes partilhadas pelos membros da elite política paranaense acerca da democracia apresentamos algumas análises que buscam testar empiricamente as hipóteses da consistência e da sofisticação da cultura política desse grupo de indivíduos que tem a política como atividade principal. Como a base de dados selecionada se restringe às elites, nossa 
análise se debruça sobre a consistência e coerência interna dos valores e atitudes políticas, verificando fundamentalmente a variação conjunta das respostas fornecidas pelos entrevistados às questões incluídas no survey. Ainda que esse não seja o procedimento mais adequado, a análise da estrutura subjacente às diferentes respostas fornecidas pelos indivíduos pode indicar a existência de dimensões e tendências coletivas, bem como a ocorrência de incoerências e idiossincrasias, tentando assim lançar luz sobre a hipótese aqui sugerida.

Para atingir nossos objetivos dividimos o presente trabalho em duas partes fundamentais. Na primeira apresentamos uma discussão teórica sobre a abordagem culturalista e seus pontos de intersecção com os estudos sobre elites. Na segunda, após algumas considerações de caráter metodológico, partimos para a apresentação e discussão dos resultados obtidos com os procedimentos de análise adotados para a identificação da estrutura mencionada anteriormente.

\section{Cultura política e elites}

Passadas mais de quatro décadas de sua publicação, The Civic Culture impressionantemente continua a ser a obra de referência quando tratamos da chamada teoria da cultura política. A despeito de todas as críticas endereçadas ao estudo pioneiro conduzido por Almond e Verba, sua tentativa de construção de uma conexão entre variáveis individuais e estruturas políticas estabeleceu um promissor programa de pesquisas que tem envolvido atualmente um número crescente de investigadores das ciências sociais.

Claramente inspirados pela sociologia compreensiva de Max Weber, esses investigadores definiram o conceito central da pesquisa como “[...] political orientations - atittudes toward the political system and its various parts, and attitudes toward the role of the self in the system."(p.12), entendendo a cultura política de uma determinada sociedade como a particular configuração dos padrões de orientações em relação aos objetos políticos partilhada por seus membros. Esse padrão supostamente poderia explicar em alguma medida as motivações que estão por trás das ações dos atores sociais no campo da política. 
Essas orientações compreenderiam níveis diferenciados de racionalidade e consciência, podendo ser divididas em três tipos básicos: cognitivas, afetivas e avaliativas. As orientações cognitivas compreenderiam os conhecimentos e crenças dos indivíduos sobre os diferentes objetos políticos. As afetivas, por sua vez se referem aos sentimentos de ligação e envolvimento dos mesmos em relação a esses alvos. Por fim, as avaliativas envolvem os julgamentos e opiniões, que podem ser entendidos como resultado da combinação dos conhecimentos e sentimentos partilhados pelos atores sociais em relação às partes que compõem o sistema político.

Ao nos referirmos aos objetos a que se dirigem tais orientações é preciso destacar que se incluem nessa categoria elementos concretos, como as estruturas de encaminhamento e satisfação de demandas, mas também a visão que cada um dos indivíduos possui sobre a sua própria atuação como ator político relevante ou não. Na obra de Almond e Verba essa espécie de auto-avaliação recebe a denominação de eficácia política subjetiva (p.168).

A partir desses aportes teóricos e defendendo a tese central de que a estabilidade e o sucesso de um sistema político qualquer depende em grande medida da existência de um grau significativo de congruência entre as instituições concretas e aos valores, crenças e atitudes políticas partilhados pelos cidadãos, os pesquisadores desenvolveram o referido estudo em uma perspectiva comparativa envolvendo cinco nações bastante diferentes entre si: EUA, Inglaterra, Alemanha, Itália e México. As conclusões a que chegaram, ainda que não pudessem responder a questionamentos sobre a causalidade entre as duas ordens de fatores envolvidos, apontavam para a associação entre estabilidade democrática e a ocorrência de um padrão de orientações subjetivas que batizaram de cultura cívica.

Os elementos centrais dessa cultura favorável seriam a moderação e a tolerância, combinando ativismo político racional com certa dose de confiança no sistema e nas elites políticas instituídas. Indivíduos que compartilham desse padrão de orientações não atribuem poderes infinitos aos ocupantes dos cargos públicos, pois apesar de não participarem a todo o momento, possuem conhecimento satisfatório sobre os mecanis- 
mos e instituições de encaminhamento de demandas, gozam de alta eficácia política subjetiva e exercem uma fiscalização atenta sobre as ações oficiais, inibindo possíveis desmandos.

Ora, se a este ou aquele regime (no caso aqui o democrático) exige da população certo grau de cultura cívica e, se a existência de uma ou mais elites é constatado sine dubio, o suposto é que tais elites políticas devem estar dotadas de alta parcela do estrato cultural dominante, no caso aqui a adesão à democracia. Ou seja, o mesmo quadro de elementos que parece comum à vida dos cidadãos ordinários, fica ainda mais evidente quando analisamos indivíduos que constituem grupo de controle do objeto e da causa (MICHELS, 2001).

A configuração favorável entre estes elementos e a demonstração empírica de existência de um grupo no comando das decisões seria o resultado de longos processos de alterações e permanências nas bases subjetivas do comportamento dos indivíduos que conduziriam tanto o cidadão comum quanto o político "[...] to a balanced political culture in wich political activity, involvement, and rationality exist but are balanced by passivity, tradicionality, and commitment to parochial values [...]" (Ibid., p. 30).

Ao sistematizar os elementos fundamentais de um programa de investigações sobre essa dimensão subjetiva dos fenômenos políticos, The Civic Culture inspirou um número expressivo de pesquisadores, mas também inúmeros críticos que tratarem de apontar limitações e equívocos em suas proposições, alguma delas bastante pertinentes.

Algumas delas apontam fragilidades próprias de um empreendimento pioneiro, como certa imprecisão na definição de cultura política que, segundo Pye (1972) teve como conseqüência o seu uso com sentidos bastante vagos pelos pesquisadores de uma primeira geração na abordagem culturalista. Felizmente essa imprecisão foi sendo relativamente corrigida por sucessivos refinamentos posteriores (ALMOND, 1989; PYE \& VERBA, 1989; LANE, 1992).

Outras críticas se debruçam sobre problemas de natureza ideológica, denunciando principalmente a adesão normativa de Almond e Verba ao paradigma minimalista schumpeteriano (PATEMAN, 1989; WIATR, 1989; ALVAREZ, DAGNINO \& ESCOBAR, 2000). Pateman afirma que ao seguir essa corrente teórica dominante nos estudos sobre a democracia no 
século XX, os autores teriam construído uma análise essencialmente ideológica que claramente celebra o status quo existente nas sociedades de capitalismo desenvolvido (1989).

Efetivamente, essa adesão normativa fica evidente com uma leitura atenta da obra e suas implicações teóricas e metodológicas não podem ser menosprezadas. Essa importante limitação só pôde ser superada quando os estudos sobre cultura política passaram a se orientar pela tentativa de interpretar as culturas políticas de cada nação em suas particularidades, buscando entender suas origens e relações com a estrutura política, sem a pretensão de classificar essas configurações a partir de tipologias arbitrárias. Um exemplo desse tipo de abordagem é a obra de Pye e Verba (1989), Political culture and political development.

Nenhuma dessas críticas, entretanto, rendeu tanta discussão quanto a que questionou a propriedade causal e a capacidade explicativa das variáveis reunidas no termo cultura política. Brian Barry (1988) se destaca como um dos principais representantes desta perspectiva crítica. Para esse autor, apesar de Almond e Verba terem sido cautelosos o suficiente para evitarem o emprego de termos que explicitassem uma relação de causalidade direta entre valores e democracia, The Civic Culture só se sustenta em sua essência através da suposição de que as variáveis que compõem a cultura política afetam os regimes democráticos. Entretanto, afirma que a natureza e extensão desse efeito não teriam sido tratadas de forma adequada, abrindo espaço para as seguintes interpretações: "some level of 'civic culture' could be held to be a necessary condition for the possession of a certain degree of 'democracy', or a sufficient condition, or a necessary and sufficient condition.” (BARRY, 1988, p. 50)

Para estabelecer de maneira segura a relação entre essas duas ordens de variáveis, Barry argumenta que teria sido necessário que os autores tivessem estabelecido critérios para definição de níveis significativos de cultura cívica e democracia ou ao menos uma escala para a disposição das nações pesquisadas, o que não foi realizado. Em razão desta fragilidade, propõe uma inversão da relação causal, ou seja, ao invés da cultura política causar a estabilidade democrática, seria mais plausível entender que as experiências sob instituições democráticas gerariam nos indivíduos os valores, crenças e atitudes congruentes com sua consolidação (Ibid.). 
Sobre esses questionamentos contundentes Almond (1989) afirma categoricamente que as orientações políticas subjetivas sempre foram tratadas, tanto no estudo inicial, quanto nos seus trabalhos posteriores, como variáveis que sofrem interferências de elementos externos, sendo tratadas ao mesmo tempo como dependentes e independentes, influenciando e sendo influenciadas pela estrutura política.

Acreditamos que a raiz desta polêmica possa ser encontrada no entendimento sobre quais as esferas onde o processo de socialização se daria. Se, por um lado, entendermos os processos que tem curso no período infantil como os únicos responsáveis pela transmissão dos valores, crenças e conhecimentos que irão estruturar as orientações e as atitudes dos atores para com os objetos políticos, estaremos propensos a encarar a cultura política como variável determinante na configuração das estruturas políticas. Entretanto, se por outro lado, também forem levados em conta os processos de socialização política da fase adulta, esta determinação deixa de ser automática e o unilateralismo deixa de fazer sentido.

Almond (1989) cita estudos realizados em países comunistas para apontar a complexidade desta relação. Os ideólogos destes regimes, de uma maneira geral, acreditavam muito na maleabilidade da cultura política da população, que poderia ser moldada através de ações empreendidas através de instituições oficiais como a escola, o partido e os meios de comunicação. Entretanto, a despeito de inúmeros esforços voltados para a formação de uma cultura comunista, isto de uma maneira geral não ocorreu. Valores, crenças e orientações existentes nos períodos pré-revolucionários demonstraram ter um alto poder de persistência, o que implicou em uma instabilidade crescente dos regimes que tiveram que sustentar seu poder através ações coercitivas.

Contrastando com estas descobertas, todavia, estudos apontaram uma alteração significativa no padrão de cultura política dos ingleses, entre as décadas de 60 e 80, devido a um desempenho governamental pouco convincente, o que se refletiu em tensões sociais e crescimento da insatisfação para com as autoridades (KAVANAGH, 1989). No mesmo sentido, alguns elementos que podem fugir da arena governativa, tais como a estabilidade econômica de uma nação, influenciam a adesão ou não às 
normas do regime democrático por parte da população (MENEGUELLO, 2005).

Uma solução provisória para esse debate talvez seja a consideração de que a validade explicativa da cultura política não pode ser tomada como um dado a priori, o que ressalta então a necessidade de estudos empíricos para testá-la como categoria explicativa em cada situação em particular (ALMOND, 1989, p. 30). Assim como seria absurdo tratar esse conjunto de variáveis como causa não-causada (nos termos tomistas), seria igualmente sem propósito desconsiderar totalmente o seu impacto sobre as instituições democráticas. Neste sentido, nos parece muito mais justificável a perspectiva que enxerga uma mútua influencia entre esses fatores culturais e estruturais.

Como os processos de democratização são realmente complexos e dificilmente poderiam ser explicados por modelos monocausais ou parcimoniosos, é possível afirmarmos que a cultura efetivamente importa e deve ser considerada como variável relevante no complexo de fatores que conduzem à implantação, consolidação, estabilidade e aprofundamento de regimes pluralistas. Assim, podemos passar aos demais questionamentos que estruturam esse trabalho: a cultura de quem importa? Os valores, crenças e atitudes políticas das elites são especialmente relevantes?

Existem questões que partem do paradigma sociológico e muitas vezes gostaríamos de responder. Seria interessante entender em que medida é o processo de socialização que torna estas elites mais "preparadas ou aptas" ou se é o arranjo institucional da democracia que faz com que os indivíduos adotem determinados valores e crenças de acordo com sua posição na complexa estrutura política. Mas nem os estudos sobre instituições, nem os que se dedicaram a estudar as atitudes e valores conseguiram contemplar esta lacuna. Os achados aqui seguem um curso convergente, ou seja, o da homogeneidade de valores de uma elite e o da importância da cultura política destas elites para o bom andamento da democracia.

A maior parte dos estudos recentes que seguem a abordagem culturalista tem se mantido fiel a tradição estabelecida por Almond e Verba no que diz respeito à focalização de unidades nacionais, sem dis- 
tinguir grupos ou subgrupos. Esses estudos têm sido realizados a partir de surveys nacionais e terminam por estabelecer um quadro da cultura política de uma sociedade como um todo.

Essa abordagem é fundamental para a compreensão dos processos de democratização, mas nos levam a pensar que, se os valores dos cidadãos comuns são relevantes, aqueles partilhados pelas elites sejam ainda mais importantes. Afinal, são as elites que representam o cidadão comum na arena política, stricto senso, nas democracias industriais.

Sobre esse assunto, Robert Dahl em seu já clássico Poliarquia (1997) apresenta argumentos bastante pertinentes. Ao discutir os fatores que favorecem o estabelecimento de regimes poliárquicos esse autor dedica todo um capítulo à discussão sobre a importância da crença dos ativistas políticos. Em uma frase que sintetiza o conjunto dos seus argumentos sobre o tema afirma que seria difícil que um regime dessa natureza pudesse vir a existir sem que uma camada politicamente atuante do país em questão acreditasse nos méritos da democracia e rejeitasse fortemente as demais alternativas de caráter autoritário. De maneira inversa, "num regime hegemônico, os líderes, presumivelmente, pelo menos, devem preferir a hegemonia a qualquer alternativa”. (p.129)

Além disto, os clássicos da teoria das elites, Mosca, Michels e Pareto, colocam a quase inegável demonstração histórica da existência de uma vanguarda que leva à frente as decisões políticas. Mesmo nos momentos onde se pensa num maior ativismo político por parte das "massas" entendemos que existiram e existem elites que "conduzem" as principais diretrizes do processo histórico. Não estamos aqui reforçando o argumento limite da incapacidade das massas, porém nos fica difícil entender o curso histórico sem que passemos pelo crivo inegável das elites políticas. Lynn Hunt apresenta em seu livro "Cultura, Política e Classe na Revolução Francesa”, parte desta demonstração empírica. (HUNT, 2007). A autora demonstra que mesmo em situações historicamente dadas onde se partia de um movimento de massas as elites tiveram papel preponderante na condução dos eventos.

Destarte, entendendo que pessoas diferentes provocam efeitos distintos em qualquer sistema político, Dahl propõe como importante questão a identificação de quem alimenta quais crenças políticas. Apesar de ressaltar 
que essa abordagem não implica na desconsideração dos valores difundidos entre o restante da população, aponta que a cultura política das camadas politicamente mais atuantes e envolvidas com as atividades políticas pode ser um importante fator explanatório nos estudos sobre poliarquias. Esses ativistas políticos, diferentemente da maioria das pessoas, teriam sistemas de crenças complexos e ricos, o que poderia ser explicado em grande medida pela associação entre essa sofisticação e os níveis de escolaridade e interesse em política. Atendo-se apenas ao componente cognitivo da cultura política, Dahl é categórico ao afirmar que é plausível supor que o conhecimento sobre os diferentes aspectos da vida política de um país qualquer seja maior entre os membros dessa elite do que entre a população geral.

Por possuírem esse sistema supostamente mais sofisticado, os ativistas também teriam a maior probabilidade de serem guiados por suas crenças. Quando mais rudimentares e desorganizadas são as crenças de um indivíduo menor são as chances de quem tais orientações guiem o seu comportamento, ou seja, exigindo um teste de congruência e densidade dos valores dos ativistas. Nas palavras do próprio autor:

“[...] uma pessoa cujo sistema de crenças contém efetivamente os pontos fundamentais da argumentação de Mill sobre a liberdade, muito provavelmente se oporá a um regime que ameace impor a censura à imprensa ou a supressão de partidos políticos. [...] Mas é muito difícil prever o tipo de regime, movimento ou partido que sofreria oposição ou respaldo de alguém cujo credo político pode ser resumido em 'os tempos estão ruins e pessoas como eu estão na pior, neste país”' (p. 130-1)

Além desses fatores que tornam as crenças desse grupo particularmente relevantes, os ativistas desempenham também papel fundamental nos processo de criação e difusão dos elementos que compõe a cultura política de uma sociedade. Tratando dos processos através dos quais se dá a incorporação das orientações políticas, Dahl se filia a autores como Rokeach (1968) ao considerar as duas primeiras décadas dos indivíduos como cruciais. Isso, entretanto, não implica na defesa da imutabilidade nos padrões de valores, pois a todo o momento os agentes são colocados diante de situações que podem levar ao questionamento de alguns ele- 
mentos que podem ser substituídos por outros. Nos tempos atuais vemos que estes padrões de valores são constantemente modificados, o que causa uma mudança também nas organizações e instituições políticas. E mais ainda, que as mudanças nas organizações e nas instituições são em grande parte conduzida por um pequeno grupo que controla os processos decisórios (PANEBIANCO, 2005). Tal mudança tem dois sentidos: vertical e horizontal. A vertical se caracteriza por uma mudança na configuração de instituições causada essencialmente pela mudança nas instituições que "ditam” o curso da história social. A horizontal se dá pelos meios e processos de socialização.

Nos termos de Dahl teríamos dois períodos de socialização. A socialização primária ocorreria em instituições como a família e a escola, pelas quais passamos em nossos períodos de infância e adolescência. A socialização secundária, por sua vez, se daria em instituições ligadas ao trabalho e outras atividades que se desenvolvem em nossa vida adulta e podem resultar no abandono de crenças antigas e na incorporação de novas. É claro que as unidades individuais experimentam as instituições de forma diferente, o que resulta não numa homogeneidade de crenças, mas numa diversidade compartilhada.

Nesses dois momentos os ativistas ou elites políticas possuem importância fundamental, pois um dos fatores que conduzem a incorporação de uma determinada crença é o prestígio de quem a transmite. Os valores e concepções políticas transmitidas por aquelas pessoas que ocupam posição de destaque na sociedade são mais facilmente assimilados pelos cidadãos médios, o que torna as elites importantes personagens não apenas na elaboração, mas também na difusão dos elementos que compõem a cultura política de uma nação ou grupo.

Também Larry Diamond (1994) na conclusão de uma interessante coletânea sobre cultura política em países em desenvolvimento, ao tentar identificar as suas fontes aponta as ações deliberadas das elites como importantes fatores. Apesar de explicitamente adotar uma abordagem que entende a cultura política como produto de grandes forças históricas e sociais, reconhece que valores, crenças e atitudes podem e freqüentemente são modificadas pela ação desses líderes. Citando exemplos como Lênin, Stalin, Hitler, Mao e Castro, mas também de lideranças favoráveis 
à democratização como Sun Yat-se, Kemal Atatürk e Mahatma Gandhi, Diamond afirma que seria difícil negar a influencia de personalidades relevantes sobre as idéias políticas, os valores, normas e sentimentos das pessoas de seu tempo (p.234). Porém não só pelo prestígio é que a reprodução opera. O controle de posições institucionais chave e o poder de determinar a conduta das instituições podem disseminar mudanças em toda a parcela de uma sociedade, como bem lembra Wright Mills (p. 176).

Como três dos estudos que compõem e citado volume sobre os casos de Taiwan (King, 1994), Turquia (Özbudun, 1994) e Índica (Sisson, 1994) demonstram, as idéias e doutrinas dessas elites continuam moldando o pensamento e as estruturas políticas de seus respectivos países mesmo após as suas mortes. O trabalho de Sisson é particularmente interessante para essa discussão sobre a interface entre a abordagem culturalista e os estudos sobre elites, pois mostra como é forte a influência de Gandhi na formação da tradição reformista na história recente da Índia através da ênfase na resolução consensual do conflito, inclusão política, igualdade social, responsividade e accountability governamental. (1994)

Em síntese, as elites importam e desconsiderar que elas exercem influência no processo político seria no mínimo ingênuo. Em conseqüência, os valores desta elite importam mais do que o da população em geral, pois, querendo ou não, são os seus membros que estão no comando do processo decisório e suas decisões afetam um leque grande de pessoas. Se a cultura política deve ser considerada um importante fator explicativo para os fenômenos políticos contemporâneos, os valores, crenças e atitudes daquelas pessoas que estão mais diretamente envolvidas nos processos políticos possuem uma relevância ainda maior. Mais ainda, nos interessa abordar a cultura política partindo do pressuposto de que as elites existem não só em grandes momentos históricos, mas em pequenas comunidades e com aspectos regionais que influenciam de sobremaneira o processo e o sistema político como um todo ${ }^{1}$.

Partindo desses pressupostos, na próxima seção nos debruçamos especificamente sobre as hipóteses da consistência estrutural dos valores políticos das elites.

Nossas aspirações teóricas e metodológicas vão de encontro ao que colocam PERISSINOTTO e BRAUNERT, 2006, em especial a introdução do texto, p. 01-03. 


\section{Procedimentos metodológicos}

Como antecipamos na introdução, nossa intenção a partir desse momento é apresentar uma proposta de análise sobre os pressupostos da sofisticação, consistência e coerência do sistema de orientações políticas subjetivas partilhadas pelos membros das chamadas elites políticas ${ }^{2}$. Como não dispomos de bases de dados adequadas para uma análise comparativa entre esse grupo e o conjunto dos cidadãos médios, recorremos aqui a um procedimento alternativo baseado na identificação de possíveis dimensões estruturais internas ao sistema de orientações partilhadas pelos indivíduos representantes desse extrato populacional.

Essa perspectiva estrutural se assenta sobre a suposição de que sofisticação e, sobretudo, a consistência são qualidades de um sistema de valores, crenças e atitudes cujos elementos constituintes tendem a variar no nível individual de maneira semelhante, associada e coerente. Tomando como exemplo a oposição clássica entre democracia e autoritarismo, ao tomarmos um conjunto de variáveis envolvendo essa dicotomia encontraríamos maior sofisticação e consistência na medida em que as respostas fornecidas pelos indivíduos seguissem uma tendência monotônica, tanto no sentido das orientações democráticas quanto das autoritárias. Assim, seria plausível afirmar que uma pessoa possuidora de um sistema coerente de orientações políticas ao responder que a democracia é a melhor forma de governo também se oponha ao governo de um líder forte que não respeite as instituições legislativas ${ }^{3}$.

Apesar de parecer algo lógico e até mesmo inescapável, recentes pesquisas têm demonstrado que a ocorrência de respostas conflitantes em questões associadas como essas são bastante comuns. A título de exem-

Para determinar quem são estas elites políticas partimos do proposto metodológico posicional de C. Wright Mills, qual seja que estas elites são formadas pelas pessoas que ocupam os principais postos de comando na hierarquia política local ou regional.

3 Aqui cabem duas observações de cunho teórico metodológico. Se a estabilidade democrática é fruto de uma cultura política minimamente desenvolvida, como desejam Putnam (1997) e Dahl (1997), seria plausível pensar que as elites políticas também compartilhassem desta cultura, ou seja, as elites são um "espelho" da sociedade. Por outro lado, outros autores sugerem que a estabilidade democrática é fruto muito mais de um cálculo feito pelas elites políticas, em aceitar a democracia como melhor forma de governo, do que a cultura política em si (PERISSINOTTO e BRAUNERT, 2006). 
plo, Moisés (2005) recentemente chamou nossa atenção para o fato de que uma parcela importante da população nacional defender uma espécie de democracia sem partidos ou congresso, portanto, sem competição eleitoral, um dos requisitos mínimos dessa forma de governo.

Seguindo a linha de argumentação defendida por Dahl (1997) incoerências dessa natureza tendem a ser menos freqüentes entre os ativistas que, devido a atributos sócio-econômicos (como alta escolaridade) e ao seu envolvimento com os assuntos políticos, possuiriam uma cultura política mais elaborada. Ou ainda, como sugere Weber, os políticos apresentam qualificações técnicas que os favorecem operar o sistema político, por isso a predominância de profissionais liberais, advogados, etc., dentre as ocupações mais comuns dos políticos. Isso, sem dúvida, gera um sistema de valores e crenças semelhantes, visto que as experiências de socialização não se diferenciam muito ${ }^{4}$.

Portanto, ao identificarmos a existência de grandes eixos estruturais gerados pela variação conjunta de respostas fornecidas a temas politicamente relacionados poderíamos concluir pela consistência interna do conjunto de orientações subjetivas que configuram a cultura política do grupo em questão. Caso o contrário se verifique e as respostas relacionadas a temas semelhantes variem seguindo um padrão próximo ao aleatório, demonstrando assim a inexistência de tendências consistentes, poderíamos concluir pela inconsistência.

A técnica estatística que melhor se adapta ao desenho de pesquisa que propomos é a análise fatorial exploratória, pois se presta ao exame dos padrões subjacentes ou relacionamentos existentes entre um grande número de variáveis. Além disso, é também a técnica ideal para determinar se as informações contidas em um conjunto de variáveis podem ser condensadas ou sumarizadas em um pequeno grupo de fatores ou componentes (HAIR; ANDERSON \& TATHAM, 1987).

\footnotetext{
Em livro recente, Mudanças na Classe Política, Leôncio Martins Rodrigues mostra que as mudanças na elite política podem advir também de uma mudança na configuração social de uma dada sociedade. Por exemplo: se em 1920 em nosso país as ocupações mais comuns dos políticos eram advocacia, engenharia e medicina, por serem "mais valorizadas socialmente", vemos que em 2005 temos uma mudança deste quadro, pois os padrões de inserção e recrutamento político exigem novas categorias de ocupações como professores, jornalistas, economistas, etc. Tais ocupações estariam de maior acordo com as exigências da carreira política no Brasil de hoje. Não ocorre que as profissões tradicionais fiquem "de fora", mas observamos a inserção de outras ocupações de acordo com a mudança na composição social do país.
} 
Sendo mais precisos, análise fatorial é um termo bastante genérico utilizado para designar uma classe de métodos estatísticos multivariados utilizados principalmente em procedimentos de redução e sumarização de dados. A redução ocorre através da análise das inter-relações existentes entre as variáveis observadas e a sua explicação por medidas latentes. Cada uma das medidas envolvidas é entendida como dependentes em relação a essas variáveis hipotéticas não observadas (Ibid).

Dentre os modelos utilizados para obtenção de soluções fatoriais optamos nesse trabalho pela chamada análise de componentes principais com Eigenvalue mínimo de 1 e rotação oblimin. A escolha desse método de rotação se deve principalmente ao fato de que em bases de dados sobre cultura política, como a que utilizamos nesse trabalho, as dimensões ou fatores extraídos geralmente estão associados. Nesse caso, não seria adequada a utilização de rotações mais comumente empregadas, como a varimax, pois o pressuposto da ortogonalidade não seria respeitado (Ibid).

Essa metodologia foi aplicada na análise de uma base de dados sobre as elites políticas do estado do Paraná produzida pela equipe do Núcleo de Pesquisa em Sociologia Política Brasileira (NUSP) da Universidade Federal do Paraná. Os dados se referem a um survey aplicado a um universo composto por deputados estaduais, ocupantes de cargos no interior dos partidos políticos e representantes da burocracia estatal (secretários, diretores de empresas estatais e ocupantes de cargos no executivo) nos dois mandatos do governador Jaime Lerner (1995-2002) e no primeiro mandato do governador Roberto Requião (2003-2006), totalizando 158 entrevistas 5 . O conteúdo das informações é bastante vasto e abrange desde informações sobre a carreira e origem social até sobre os valores, crenças e atitudes políticas dos pesquisadores. É sobre este bloco específico de variáveis que iremos nos debruçar.

Não foi possível entrevistar todos os 162 deputados do período. Muitas vezes coincidiram cargos e mandatos, em outras ocorreram mudanças que não contemplaram tempo suficiente de ocupação, qual seja, 3 meses ocupando mandato de deputado estadual. Portanto, foram pesquisados apenas aqueles que ocuparam cargos por um período maior do que 90 dias e se dispuseram a responder á entrevista. Com esses critérios e limitações, o universo total da pesquisa foi de 95 indivíduos que formaram a elite durante os dois mandatos do governo Lerner e o primeiro do governo Requião, sendo que a amostra representa $58,30 \%$ do mesmo. 


\section{A estrutura da cultura política das elites}

Abaixo (TABELA 1) apresentamos os resultados encontrados com a realização da análise fatorial envolvendo 27 variáveis sobre diferentes temas relacionados à democracia. Antes de passarmos a apresentação e discussão dos nossos achados alguns esclarecimentos sobre a tabela se fazem necessários. Como é possível verificar, ao estipularmos um Eigenvalue mínimo de 1, foram extraídos 8 componentes ou fatores que poderiam contribuir para a explicação de $63,4 \%$ da variação conjunta dos dados. Em cada uma das linhas que representam as variáveis podem ser identificadas duas células em destaque, uma mais escura e outra mais clara. A escura indica a maior carga fatorial, informando que a variável em questão é melhor explicada pelo fator cuja coluna está destacada. A célula mais clara indica a segunda maior carga fatorial para cada medida. Assim, para identificar as variações conjuntas entre as medidas devemos observar quais delas possuem células em destaque em colunas coincidentes. Essas coincidências formam o que classificamos de eixos estruturais da cultura política do grupo. Por fim, para a exposição dos resultados optamos por seguir a ordem dos componentes representados pelas colunas.

No primeiro componente verificamos um significativo agrupamento de medidas obtidas com questões que colocam os entrevistados diante de situações hipotéticas nas quais o fim da democracia seria justificável, tais como a ameaça à propriedade privada, aos valores morais e religiosos, o descontrole da corrupção, dentre outros. Diante de cada uma dessas situações os entrevistados foram levados a manifestarem o seu grau de concordância.

Tal padrão de variação conjunta poderia ser inicialmente constatado por uma simples análise das freqüências percentuais das respostas fornecidas pelos indivíduos em cada uma das perguntas, como fica claro na Tabela 2. A elite entrevistada manifesta em toda a bateria uma tendência defensora da democracia adiante das diferentes ameaças hipotéticas, discordando majoritariamente de cada uma das seis proposições iniciais e concordando com a última. 
TABELA 1 - RESULTADOS DA ANÁLISE FATORIAL EXPLORATÓRIA

Componente

A democracia é a melhor forma de governo

O Brasil é uma democracia atualmente

Só há democracia se houver participação pelo voto

Só há democracia se houver participação por plebiscitos

Só há democracia se houver participação por conselhos gestores

Só há democracia se houver participação por orçamentos participativos

Só há democracia se houver participação direta em todas as decisões políticas

A política é complexa e deve ser deixada às lideranças políticas

A ganância das elites é um obstáculo à democracia no Brasil

A desigualdade de renda é um obstáculo à democracia no Brasil

A falta de educação do povo é um obstáculo à democracia no Brasil

O desrespeito aos direitos humanos é um obstáculo à democracia no Brasil

A agitação social é um obstáculo à democracia no Brasil

A corrupção nos órgãos públicos é um obstáculo à democracia no Brasil

A violência e o crime organizado são um obstáculo à democracia no Brasil

Ameaça generalizada à propriedade privada justifica fim da democracia

Ameaça generalizada aos valores morais e religiosos justifica fim da democracia Ameaça à ordem pública em função de crise econômica justifica fim da democracia

Descontrole da corrupção justifica fim da democracia

Ameaça ao estado pelo crime organizado justifica fim da democracia

Quebra da hierarquia das instituições militares justifica o fim da democracia

O fim da democracia não é aceitável em hipótese alguma

Favorável a manutenção do atual sistema universitário gratuito

Favorável a universalização da saúde pública

Favorável a renda mínima para todos os cidadãos com dinheiro público

Favorável a cotas para negros nas universidades públicas

Reforma agraria em grandes propriedades privadas (produtivas ou improdutivas)

Fonte: Núcleo de Pesquisa em Sociologia Política Brasileira - UFPR

Notas: Extração por Análise de Componente Principal

Rotação Oblimin com Normalização Kaiser

8 componentes extraídos a partir do mínimo de 1 para o Eigenvalue

$63,4 \%$ de variação explicada

\begin{tabular}{|c|c|c|c|c|c|c|c|}
\hline 1 & 2 & 3 & 4 & 5 & 6 & 7 & 8 \\
\hline,- 152 & ,098 &,- 082 & ,070 & , 177 &,- 824 & ,075 &,- 055 \\
\hline,- 001 &,- 198 & -,097 &,- 124 & 655 &,- 198 & , 189 & , 105 \\
\hline,- 233 &, 144 & 023 &,- 002 & ,735 &,- 022 &, 014 &,- 010 \\
\hline,- 038 & 661 & 166 & 281 & ,098 &,- 265 &,- 327 & 325 \\
\hline,- 048 & 818 & ,094 &, 030 &,- 057 &, 113 & ,056 &,- 038 \\
\hline-018 & 819 & ,004 & 317 &, 151 &,- 223 & 041 &, 194 \\
\hline ,061 & ,368 & ,070 & 204 &,- 011 &,- 076 &,- 038 & 659 \\
\hline , 183 &,- 132 &,- 149 &,- 163 & ,061 & ,317 &, 129 & 623 \\
\hline $\begin{array}{l}-, 150 \\
-15\end{array}$ & 207 & 377 & 616 & -,090 & -131 &,- 263 &,- 032 \\
\hline,- 135 &,- 038 & 615 & ,092 &,- 139 &,- 118 & ,407 &, 006 \\
\hline ,088 & ,011 & 480 &,- 177 &,- 261 &, 183 &,- 101 &,- 348 \\
\hline ,056 & ,225 &, 556 & ,387 & ,364 & ,026 &,- 153 &,- 229 \\
\hline 244 &,- 015 & 511 &,- 231 & ,099 &,- 268 &,- 301 & 283 \\
\hline -,080 & ,078 & 622 & ,377 & 232 & -057 & -094 & -102 \\
\hline, 136 &, 164 & 675 &, 085 &,- 034 & 077 &, 076 & 01 \\
\hline 803 &,- 073 & ,036 &,- 203 &,- 038 & ,213 &,- 136 &, 060 \\
\hline 823 & 001 &,- 055 &,- 037 &,- 059 &, 215 & 019 & 092 \\
\hline ,775 &,- 099 &, 159 &,- 026 &,- 110 &,- 144 & ,098 & 135 \\
\hline 825 &,- 174 & 178 &,- 024 &,- 175 &,- 068 & 074 & , 191 \\
\hline ,918 &,- 060 & , &,- 133 &,- 073 & ,178 &,- 023 & 13 \\
\hline 780 &,- 034 &, 045 & -,095 &,- 045 &,- 065 &, 021 & 140 \\
\hline,- 786 &,- 119 & ,007 & 209 & ,084 &,- 163 & 146 &,- 032 \\
\hline,- 135 & ,392 & 121 & ,447 & 342 & ,043 & ,431 & ,045 \\
\hline ,065 & ,053 & ,065 & , 154 & 149 &,- 075 & 770 & 082 \\
\hline ,025 & 191 & -,026 & 619 & 153 & ,310 & , 110 & , 189 \\
\hline,- 037 & 124 & ,092 & 693 &,- 082 &,- 169 & 203 & ,070 \\
\hline,- 230 &, 184 &, 016 & 686 & 010 &,- 069 &, 105 & -108 \\
\hline
\end{tabular}


TABELA 2

SITUAÇÕES EM QUE O FIM DA DEMOCRACIA SE JUSTIFICA (\%)

\begin{tabular}{l|r|r}
\hline \multirow{2}{*}{ VARIÁVEL } & \multicolumn{2}{|c}{ RESPOSTAS } \\
\cline { 2 - 3 } & Concordo & Discordo \\
\hline - Ameaça generalizada à propriedade privada justifica fim da & 69,2 & 30,8 \\
- Aemocracia & 72,9 & 27,1 \\
$\quad$ Ameaça generalizada aos valores morais e religiosos justifica & 79,6 & 20,4 \\
fim da democracia & 75,8 & 24,2 \\
- Ameaça à ordem pública em função de crise econômica & 71,5 & 28,5 \\
- justifica fim da democracia & & \\
- Ameantrole da corrupção justifica fim da democracia & 84,7 & 15,3 \\
- democracia & 28,8 & 71,2 \\
\hline
\end{tabular}

Fonte: Núcleo de Pesquisa em Sociologia Política Brasileira - UFPR

Essa abordagem descritiva, entretanto, não indica se existe coerência no nível individual, ou seja, não informa se o entrevistado $x$ manteve ao longo das suas respostas uma tendência monotônica em direção à defesa da democracia ou não. Esse tipo de informação só pode ser obtida por meio da análise multivariada.

Em todas essas sete medidas encontramos cargas fatoriais bastante elevadas que vão de 0,775 a 0,918 (os valores possíveis vão de -1,0 a 1,0) indicando uma coerência acentuada em relação a esse eixo estrutural. Os membros da elite paranaense tendem a se posicionar de uma mesma maneira em todos os itens que compõem esse grupo, ou seja, aqueles que não vêem a ameaça à propriedade privada como justificativa para o fim da democracia também tendem a manter essa postura em relação a outras possíveis justificativas.

Essa orientação coerente se confirma quando verificamos que o último item agrupado na coluna possui carga fatorial negativa. Essa medida corresponde à concordância dos entrevistados à afirmação de que o fim da democracia não seria justificável em nenhuma hipótese, logo, seu sentido vai em direção oposta à dos demais itens. Assim, indivíduos que responderam negativamente as seis questões anteriores tendem a se posicionar positivamente nessa e vice-versa. Ao realizarmos uma nova análise fatorial envolvendo apenas essas medidas agrupadas verificamos 
que um único fator ou medida latente poderia explicar a variação conjunta em mais de $69 \%$.

É possível identificar outras três variáveis que tiveram suas segundas maiores cargas fatoriais na primeira coluna, mas todas com valores baixos o que também corrobora os nossos argumentos.

A base de dados possui também uma interessante bateria de variáveis relacionadas ao que podemos chamar de dimensão participativa da democracia, obtidas através da identificação do grau de concordância das elites em relação a afirmações que condicionam a existência da democracia à ocorrência da participação pelo voto, por plebiscitos, por conselhos gestores e por orçamentos participativos. Dentre essas medidas teoricamente relacionadas verificamos na coluna correspondente ao segundo componente que apenas três tiveram suas maiores cargas fatoriais com variação conjunta. Com valores que podem ser considerados altos, as questões relativas à participação em plebiscitos $(0,661)$, conselhos $(0,818)$ e orçamentos $(0,819)$ foram respondidas de maneira associada pelos entrevistados. A variável sobre o voto não aparece envolvida nesse componente, o que pode ser interpretado como indício de coerência, pois as três questões que aparecem agrupadas dizem respeito a modalidades de participação que não se referem diretamente à forma representativa.

Essa exclusão, a propósito, já poderia ser antecipada com a observação das freqüências percentuais das variáveis agrupadas no componente (TABELA 3). Podemos verificar que a quase totalidade dos membros dessa elite política consideram o voto como um elemento fundamental da democracia, mas no que diz respeito a práticas de participação mais diretas o consenso deixa de existir. Mesmo entre as medidas que foram agrupadas no componente constatamos variações significativas nas freqüências. Apesar da opção “concordo” ter sido majoritária em todas as questões é preciso notar que essas modalidades de participação mais diretas não são ainda objetos de consenso na caracterização da democracia entre os entrevistados. 
TABELA 3

RELAÇÕES ENTRE PARTICIPAÇÃO POLÍTICA E DEMOCRACIA (\%)

\begin{tabular}{l|c|c|c}
\hline \multirow{2}{*}{ VARIÁVEL } & \multicolumn{3}{|c}{ RESPOSTAS } \\
\cline { 2 - 4 } & Concordo & $\begin{array}{c}\text { Não concorda, } \\
\text { nem discorda }\end{array}$ & Discorda \\
\hline - Só há democracia se houver participação pelo voto & 95,6 & 2,5 & 1,9 \\
- Só há democracia se houver participação por plebiscitos & 41,8 & 23,4 & 34,8 \\
- Só há democracia se houver participação por & 67,5 & 10,2 & 22,3 \\
$\begin{array}{l}\text { conselhos gestores } \\
\text { - Só há democracia se houver participação por }\end{array}$ & 53,5 & 12,1 & 34,4 \\
\hline
\end{tabular}

Fonte: Núcleo de Pesquisa em Sociologia Política Brasileira - UFPR

Independentemente dessas considerações sobre o caráter participacionista ou não das crenças políticas da elite paranaense, o que queremos destacar é que as respostas fornecidas pelos seus integrantes seguem uma pauta coerente e a maioria daqueles que se posicionam favoravelmente a uma dessas modalidades tende a se posicionar de forma semelhante nas outras. Da mesma forma, os que rejeitam uma delas mantém essa postura em relação às demais modalidades de ação participativa.

O terceiro componente gerado pela análise fatorial agrupou um conjunto de questões que tratam de possíveis obstáculos à democracia no contexto nacional, a saber: desigualdade de renda, falta de educação do povo, desrespeito aos direitos humanos, agitação social, corrupção nos órgãos públicos, violência e crime organizado. É interessante notar que esses obstáculos possuem características e causas bastante distintas, sendo alguns relacionados à atuação das elites, como o item referente à corrupção, e outros ligados a questões econômicas estruturais como a desigualdade.

Ainda que em um primeiro momento essa variação conjunta das respostas possa ser interpretada como sinal de certa inconsistência, também podemos entender que por acreditarem que a democracia brasileira ainda não se encontra consolidada, as elites paranaenses tendem a identificar todos esses problemas como reais obstáculos, sem fazer distinções a partir de suas diferentes características. A postura pró-democracia identificada quando discutimos o primeiro componente da análise fatorial, aqui também aparece de maneira consistente sob esse ponto de vista. Nesse caso, não seriam as características particulares a cada tipo de pro- 
blema que teria conduzido ao agrupamento, mas o fato de ameaçarem em alguma medida algo valorizado: o regime democrático.

Compondo o que podemos chamar de fator distributivista ou igualitarista, na quarta coluna da Tabela 1 podemos encontrar um grupo interessante de variáveis que possuem em comum o fato de se referirem a políticas públicas que, ao menos em tese, visam reduzir as desigualdades sociais.

Para compor essas medidas os organizadores da pesquisa perguntaram aos entrevistados se os mesmos eram favoráveis à manutenção do atual sistema universitário gratuito, a renda mínima para todos os cidadãos com dinheiro público, às cotas para negros nas universidades públicas e à reforma agrária em grandes propriedades privadas. A primeira delas teve uma carga fatorial moderada $(0,447)$ no fator em questão, porém as demais, cujo caráter é relativamente mais polêmico, as cargas se elevaram consideravelmente, sendo 0,619 a menor. Portanto, entrevistados que se declararam favoráveis a uma dessas políticas tenderam a manter essa mesma disposição em relação às demais, revelando certa coerência nas escolhas. O mesmo pode ser dito dos que se manifestaram contrários.

Merece destaque o fato da medida referente à universalização da saúde pública não ter sido incluída nesse componente. Nessa variável verificamos o maior percentual de ocorrência de respostas positivas $(96,2)$ e devido a esse quase consenso a análise fatorial realmente não poderia reuni-la a propostas polêmicas como as cotas para minorias e a reforma agrária. Ainda que os entrevistados se dividam em relação às demais políticas, no caso da saúde para todos o consenso é quase perfeito.

Além dessas variáveis que diretamente interrogam os entrevistados sobre ações que potencialmente minimizariam as desigualdades sociais, outra medida com formulação bastante distinta teve sua maior carga fatorial $(0,616)$ localizada nesse componente igualitarista ou distributivista. Trata-se da obtida através do grau de concordância dos entrevistados em relação à afirmação de que a ganância das elites seria um obstáculo à democracia no Brasil e tal resultado corrobora nosso argumento em favor da coerência dos entrevistados em relação a essa dimensão.

O quinto componente nos remete a questão das condições para a existência da democracia, já abordada anteriormente quando apresenta- 
mos os resultados referentes ao segundo componente. Informamos naquele momento que a participação por meio do voto não havia sido agrupada às demais formas devido ao seu caráter representativo que destoava das demais, ligadas à participação direta. Naquele momento vimos essa separação como indicativo de coerência, o que parece ser confirmado quando analisamos as cargas fatoriais na quinta coluna da Tabela 1. Nela constatamos que apenas duas variáveis foram agrupadas, sendo elas a medida sobre o voto como condição para a democracia $(0,735)$ e uma outra gerada pelo grau de concordância dos indivíduos em relação à afirmação de que o Brasil é uma democracia atualmente $(0,655)$. Esse resultado indica que os indivíduos que vêem o voto como principal instrumento de participação são os que tendem a concordar que o Brasil é uma democracia, o que não ocorre entre aqueles que consideram formas mais diretas de participação como fundamentais à configuração dessa forma de governo.

O sexto fator não apresenta agrupamento, com apenas uma variável localizada. A medida relacionada à concordância dos entrevistados à afirmação de que a democracia é a melhor forma de governo registrou uma carga fatorial elevada e negativa $(-0,824)$. Esse dado causa certa estranheza, pois esperávamos que a mesma fosse se agrupar no eixo relacionado as orientações participacionistas. Na verdade, com tamanha carga fatorial não poderíamos concordar com a inclusão dessa variável em nenhum dos outros eixos estruturais, pois a sua segunda carga fatorial mais elevada foi de apenas 0,177 na coluna 5. Além disso, nem mesmo ao analisarmos as segundas maiores cargas fatoriais dessa coluna encontramos cargas consideráveis, sendo a maior de apenas 0,310. Portanto, aqui identificamos um problema considerável no que diz respeito à coerência estrutural interna das orientações subjetivas dessa elite. Essa variável, denominada de "posição churchilliana" é comumente empregada como indicador de apoio à democracia e, ao menos em tese, deveria variar em conjunto com disposições de defesa à democracia no interior de um sistema de crenças sofisticado, o que não encontramos aqui.

Situação menos grave nós encontramos na sétima coluna onde também apenas uma variável teve sua maior carga fatorial localizada. Trata-se 
da medida já mencionada e discutida anteriormente sobre a posição dos indivíduos sobre a universalização da saúde pública.

O mais grave problema que a análise fatorial apontou está na última coluna da Tabela 1, pois nela podemos encontrar duas variáveis teoricamente opostas reunidas com cargas fatoriais importantes. A primeira é obtida a partir do grau de concordância dos entrevistados acerca das afirmações de que só há democracia se houver participação direta em todas as decisões políticas e a segunda representa a concordância com a idéia de que a política é complexa e deve ser deixada às lideranças políticas. Esse dado indica, portanto, que existe variação conjunta entre as duas medidas o que pode ser interpretado como um forte indício de inconsistência. Na realidade poderíamos esperar que ambas estivessem reunidas em um componente, mas para isso uma delas deveria apresentar carga fatorial negativa indicando variação em direções contrárias. Tomando como pressuposto a tese da consistência e coerência dos valores dessa elite esperávamos que os defensores da participação ampla nos processos decisórias tenderiam a se posicionar de maneira contrária a tese da complexidade da política e da condução das massas pela elite. Esse quadro, entretanto, não foi verificado.

Encarando a difícil tarefa de sintetizar os resultados apresentados ao longo dessa seção, somos levados a afirmar a hipótese da consistência e coerência interna dos valores e atitudes dos entrevistados. O conjunto das variáveis que compõe a base de dados utilizada nessa investigação claramente se agrupa em eixos que no geral dão forma ao que podemos chamar de estrutura dimensional de valores consistente. A maioria das medidas, agrupadas até a quinta coluna, manifestou variação conjunto plausível e distante de um padrão aleatório, mostrando que as opções das elites entrevistadas seguem uma tendência consistente. Essa conclusão geral, entretanto, não pode nos conduzir a desconsideração dos graves problemas que aparecem nas colunas que reúnem as demais variáveis. Essas incoerências merecem ser objeto de análises posteriores que podem indicar explicações para tais idiossincrasias ou, no mínimo, apontar para a necessidade de refinamentos nos instrumentos e coleta de dados. 


\section{Considerações finais}

Uma análise adequada dos pressupostos da sofisticação e coerência do sistema de valores e crenças de uma elite política, como já apontamos anteriormente, deveria adotar um procedimento comparativo na análise de dados de survey que confrontasse as orientações desse grupo com aquelas partilhadas pela população em geral, composta pelos "homens comuns” que não tem a política como atividade fundamental.

Infelizmente uma base de dados dessa natureza não está disponível atualmente e a sua produção envolveria um volume significativo de recursos. As pesquisas que têm sido desenvolvidas sobre cultura política em nosso país ou tem se dedicado a grupos específicos, como os membros de conselhos gestores (PERISSIONOTTO, FUKS e RIBEIRO, 2003, RIBEIRO, 2002) ou a estudos com base em amostras nacionais (MOISÈS, 1995), estaduais ou municipais (CASTRO, 1995). Em nenhum deles ocorreu a repetição da coleta de dados entre as elites ou ativistas políticos. Alguns pesquisadores realizaram trabalhos interessantes sobre os valores e concepções políticas desses atores sociais (REIS e CHEIBUB 1995; REIS, 2000), mas a comparação para identificação de diferenciais de sofisticação e consistência permanece como tarefa a ser realizada.

Foi diante dessa lacuna que esse artigo foi pensado como uma proposta inicial de análise alternativa. Diante das dificuldades envolvidas no procedimento comparativo propomos o emprego de técnicas multivariadas como recurso para a identificação do que definimos como consistência estrutural do conjunto de orientações subjetivas partilhadas por uma elite política específica. Nesse sentido, não nos preocupamos tanto com a produção de evidências robustas que conduzissem a conclusões efetivas sobre a sofisticação ou coerência da cultura política do grupo, mas sim com a proposição de um modelo de análise.

Acreditamos que o presente artigo colocou um modelo de análise viável e demonstrou de forma coerente a consistência dos valores da elite política paranaense. O maior ganho desta apresentação recai justamente em testar uma proposição teórica em vista de algumas proposições de clássicos da ciência política. Ou seja, mostramos que é sim possível conduzir pesquisas que aliem cultura política e elites políticas, sejam regionais ou não. 


\section{Referências bibliográficas}

ALMOND, Gabriel \& VERBA, Sidney. The Civic Culture: political attitudes and democracy in five nations. Nova York: Sage, 1989.

ALMOND, Gabriel. The intelectual history of the civic culture concept. In: ALMOND, Gabriel \& VERBA, Sidney (orgs.) The Civic Culture Revisited. London: Sage, 1989.

ALVAREZ, S; DAGNINO, E. \& ESCOBAR, A. (orgs). Cultura e política nos movimentos sociais latino-americanos: novas leituras. Belo Horizonte: Ed. UFMG, 2000.

BARRY, Brian. Sociologists, Economists, and Democracy. Chicago: Chicago University Press, 1988.

CASTRO, Henrique C. A democracia em cheque: um estudo de cultura política entre os porto-alegrenses. Dissertação de Mestrado apresentada ao Programa de Pós-graduação em Ciência Política da Universidade Federal do Rio Grande do Sul, 1995.

DAHL, Robert. Poliarquia. São Paulo: Edusp, 1997.

DALTON, Russel J. Value change and democarcy. In.: PHARR, Susan J.; PUTNAM, Robert D. (eds.). Disaffected Democracies: what's troubling the trilateral countries? Princeton: Princeton University Press, 2000.

DIAMOND, Larry. Political Culture and Democracy in Developing Countries. London: Lynne Rienner, 1994.

FUKS, Mario; PERISSINOTTO; Renato M. \& RIBEIRO, Ednaldo A. Cultura política e desigualdade: o caso dos conselhos municipais de Curitiba. Rev. Sociol. Polit., no.21, p.125-145, 2003. 
HAIR, Joseph F.; ANDERSON, Ralph E.; TATHAM, Ronald L. Multivariate data analysis. New York: Macmillan, 1987.

HUNT, Lynn. Política, Cultura e Classe na Revolução Francesa. São Paulo: Companhia das Letras, 2007.

INGLEHART, Ronald; WELZEL, Christian. Modernization, cultural change, and democracy: the human development sequence. New York, Cambridge University Press, 2005.

KAVANAGH, Dennis. Political culture in Great Britain: the decline of the civic culture. In: ALMOND, Gabriel \& VERBA, Sidney (orgs.) The Civic Culture Revisited. London: Sage, 1989.

KING, Ambrose Y.C. A nonparadigmatic search fo democracy in postconfucian culture: the case of Taiwan, R.O.C. In: DIAMOND, Larry. Political Culture and Democracy in Developing Countries. London: Lynne Rienner, 1994.

LANE, Ruth. Political Culture: Residual Category or General Theory? Comparative Political Studies, v. 25, n. 3, p. 362-387, 1992.

MENEGUELLO, Rachel. (2005). Percepções públicas do Congresso Nacional: o paradoxo da democracia brasileira. Disponível em: http:// www.comciencia.br/reportagens/2005/07/14.shtml. Acesso em 10 de janeiro de 2008.

MICHELS, Robert. (1989) 2001. Para uma sociologia dos partidos políticos na democracia moderna. Lisboa: Editora Antígona.

MOISÉS, José A. A desconfiança nas instituições democráticas. Opinião Pública, v.11, n.1, p. 33-63, 2005.

MOSCA, Gaetano. (1992). La Classe Politica. México: Fondo de Cultura Economica. 
MULLER, Edward N.; SELIGSON, Mitchel. Civic culture and democracy: The question of causal relationships. In: American Political Science Review, n.88: 635-652, 1994.

NORRIS Pippa. Democratic Phoenix: political activism worldwide. Cambridge: Cambridge University Press, 2002.

ÖZBUDUN, Ergun. State elites and democratic political culture in Turkey. In: DIAMOND, Larry. Political Culture and Democracy in Developing Countries. London: Lynne Rienner, 1994.

PANEBIANCO, Angelo. Modelos de partido. Organização e poder nos partidos políticos. São Paulo: Martins Fontes, 2005.

PATEMAN, Carole. The Civic Culture: a philosophic critique. In.: ALMOND, Gabriel \& VERBA, Sidney (orgs.) The Civic Culture Revisited. London: Sage, 1989.

PERISSINOTTO, Renato Monseff; BRAUNERT, Mariana B. A direita, a esquerda e a democracia: os valores políticos dos parlamentares paranaenses (1995-2002). In: Revista Opinião Pública, vol. 12, nº 01, Apr/May, 2006.

PUTNAM, Robert. Comunidade e Democracia: a experiência da Itália moderna. Rio de Janeiro: Fundação Getúlio Vargas, 1997.

PYE, Lucian W. Culture and Political Science: Problems in the Evaluation of the Concept of Political Culture. Social Science Quarterly, v. 53, n.2, p. 285-296, 1972.

PYE, Lucian. W. \& VERBA, Sidney (eds.) Political Culture and Political Development. Delhi: Surjeet, 1989.

REIS, Elisa P. Percepções das elites seobre a pobreza e a desigualdade. Revista Brasileira de Ciências Sociais, vol. 15, n. 42, 2000. 
REIS, elisa P; Cheibub, Zairo B. Valores políticos das elites e consolidação democrática. Dados, vol. 38, n. 1, 1995.

RIBEIRO, Ednaldo A. Cultura política e teoria da democracia: implicações empíricas de um debate teórico. Revista Mediações, v.7, n.1, p. 113140, 2002.

RODRIGUES, Leôncio Martins. Mudanças na Classe Política Brasileira. São Paulo: Publifolha, 2006.

ROKEACH, Milton. Beliefs, attitudes and Values. São Francisco: JosseyBass, 1968.

SISSON, Richard. Culture and democratization in India. In: DIAMOND, Larry. Political Culture and Democracy in Developing Countries. London: Lynne Rienner, 1994.

WEBER, Max. Economia e Sociedade. Vol 2. São Paulo: Editora UnB/ Imprensa Oficial, 2004.

WIATR, Jerzy J. The Civic Culture from a Marxist-Sociological Perspective. In.: ALMOND, Gabriel \& VERBA, Sidney (orgs.) The Civic Culture Revisited. London: Sage, 1989.

WRIGHT MILLS, C. A Elite do Poder. $4^{\mathrm{a}}$ Ed. Rio de Janeiro: Zahar Editores, (1965) 1981. 